Z. Klin. Chem. Klin. Biochem.

13. Jg. 1975 , S. $395-400$

\title{
Quality Control in Hematology by Means of Values from Patients
}

\author{
By W. P. F. Rutten, R. J. H. Scholtis, N. A. Schmidt and R. J. M. van Oers
}

Stichting Medische Laboratoria Breda, The Netherlands

(Eingegangen am 11. Oktober 1974/1. April 1975)

Summary: The results of the analyses which were obtained with the Hemalog for the determination of platelets, white blood cells, red blood cells, hemoglobin and hematocrit were statistically analysed for the quality control of the determinations.

Now that the testing method has been applied for 6 months, it appears from the results that it is extremely suitable for the determination of hemoglobin, red blood cells and the hematocrit and, to a lesser extent, for white blood cells and platelets.

\section{Qualitätskontrolle in der Hämatologie mittels Patientenwerten}

Zusammenfassung: Mit dem Hemalog erhaltene Analysenergebnisse für Thrombo-, Leuko- und Erythrocyten sowie Hämoglobin und Hämatokrit werden zwecks Qualitätskontrolle statistisch untersucht.

Die Ergebnisse zeigen, daß die jetzt über 6 Monate angewandte Testmethode sehr gut für die Kontrollen von Hämoglobin, Erythrocyten und Hämatokrit, weniger auch von Leuko- und Thrombocyten geeignet ist.

\section{Introduction}

The quality control in hematology with the aid of quality control material is not easy. In the first place the material will keep only for a short time and in the second place the material is not cheap.

In our laboratory we have an automated analysing apparatus, the Hemalog (Messrs. Technicon, Tarrytown. New York) for the determination of platelets ${ }^{1}$ ), white blood cells, red blood cells, hemoglobin (Hb) and hematocrit (PCV) from which the results are fed into a computer.

Statistical quality control is therefore obviously required. In the literature many methods have been proposed for the control the quality of determinations by calculating the daily averages of results from patients. $(1,2$,

\footnotetext{
1) Abbreviations:

PBC = Platelet Blood Corpuscles

WBC $=$ White Blood Corpuscles

RBC $=$ Red Blood Corpuscles

PCV = Packed Cell Volume, Hematocrit

MCV = Mean Cell Volume

MCH = Mean Cell Hemoglobin

MCHC $=$ Mean Cell Hemoglobin Concentration
}

3). This method appears to be quite useful when there is a small physiological deviation in the measured value. It is a well known fact that for normal people the cell constants $\mathrm{MCH}\left(\frac{\mathrm{Hb}}{\mathrm{RBC}}\right), \mathrm{MCHC}\left(\frac{\mathrm{Hb}}{\mathrm{PCV}}\right)$ and $\mathrm{MCV}\left(\frac{\mathrm{PCV}}{\mathrm{RBC}}\right)$ do not vary greatly $(4,5)$. This makes them extremely valuable for the control of the hemoglobin, red blood cells, and the hematocrit in normal persons by calculating the mean value. In order not to get into a vicious circle, it is necessary to know that one of the three measured values is right.

We have done this by calculating the average for the hemoglobin. The hemoglobin has been chosen because we can always calibrate the amount of hemoglobin in an absolute sense by means of the molecular coefficient of extinction of the cyanide-hemiglobin (6). Platelets and white blood cells are controlled by calculating the average. The described method is easily practicable. The only condition is that there are enough patient values close to the normal range. Because mostly the number of normal patients per series was sufficiently great, we have calculated the average after each series and have not waited till the end of the day to calculate the daily average. 


\section{Methods}

The results used in this study have been obtained from the Hcmalog. This instrument simultaneously determines from one sample the value for platelets $(\mathrm{PBC})$, white blood cells. (WBC), red blood cells $(\mathrm{RBC})$, hemoglobin $(\mathrm{Hb})$ and the hematocrit (PCV). Moreover the system calculates the derived values, the MCV, the MCH, the MCHC. Sample preparation and operation of the Hemalog are described earlier (7).

\section{Distribution of the mean}

For quality control reasons we use the series mean of the hemoglobin of men, the hemoglobin of women, $\mathrm{MCV}, \mathrm{MCH}, \mathrm{MCHC}$, platelets and white blood cells.

Becker et al (8) and Frederick (9) found a normal distribution for the hemoglobin of men, hemoglobin of women, $\mathrm{MCV}, \mathrm{MCH}$ and MCHC. From this fact it follows that the series means of these values are also normally distributed (10).

Becker et al (8) gives for the white blood cells a skewed distribution. We found the same distribution for the platelets. The mean of a skewed distribution will have a normal distribution if the number out of which the mean is determinated is great enough (10).

Because we calculate an average of at least 30 samples, we can assume that the mean of white blood cells and platelets will have a normal distribution.

We have given a Kolmogorov-Smirnov (K-S) test on these two means. These tests showed that our assumption was right.

\section{Quality control}

Each batch has been checked by calculating the average of the hemoglobin of men $(\overline{\mathrm{Hbd}})$, of the hemoglobin of women $(\overline{\mathrm{Hb}})$, the average of the MCV $(\overline{\mathrm{MCV}})$, of the MCHC $(\overline{\mathrm{MCHC}})$ of the $\mathrm{MCH}(\overline{\mathrm{MCH}})$, of the platelets and the white blood cells.

There are three reasons for the wide variation of the average (11):

1. Extreme values in the patient population cause the average to deviate greatly. This can be reduced by establishing truncation limits.

2. Fluctuations in the nature of the population have an influence on the average. In this study we have taken only adults. We have distinguished between the $\mathrm{Hb}$ for men and women.

3. The variation in the series average gets too great if the number of determinations in the series is too small. In this study we have used a minimum number of 30 determinations (12).

The numerical values of each statistic vary about a mean value and the bounds of the allowed variability action limits are set at the average plus or minus about 2 times standard deviation. Because the means have distributed normally - as demonstrated above - it follows that the action limits are set on about $95 \%$ confidence limits.

\section{Hemoglobin, red blood cells and hematocrit}

The starting point was that cell constants for normal persons do not vary much. Men with a $\mathrm{Hb}$ between 8.7 and $10.9 \mathrm{mmol} / \mathrm{l}$ $\mathrm{Fe}$ and women with $\mathrm{Hb}$ between 7.5 and $9.7 \mathrm{mmol} / \mathrm{Fe}$ are considered normal persons. For patients within these truncation limits the mean of the hemoglobin for men, the hemoglobin for women, the mean of the MCH, MCHC, MCV is calculated.

First checked the correctness of the $\mathrm{Hb}$ averages. If the averages are within the action limits they are considered correct. Any deviation is to be considered in connection with $\mathrm{MCH}$ and MCHC averages (fig. 1).

A deviation alone in $\mathrm{MCH}$ and $\mathrm{MCHC}$ mean can also be an indication that the measured hemoglobin values are not correct. A supposed error is confirmed by determining the hemoglobin value for a number of samples with the cyanide-hemiglobin method with a spectrophotometer.

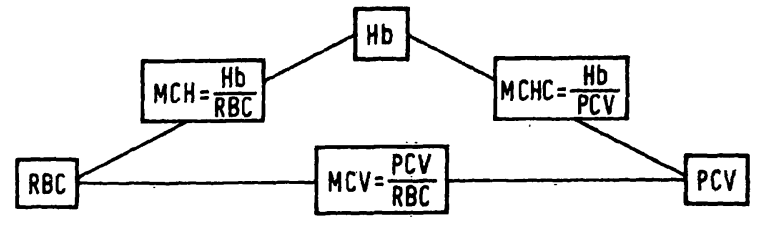

Fig. 1. Correlation between $\mathrm{MCH}, \mathrm{MCHC}$ and $\mathrm{MCV}$

\section{1}

If the $\mathrm{Hb}$ is correct and the average of the MCH and MCV fall out of their respective action limits, it is likely that the determination for the red cells is not correct (fig. 1). If the $\mathrm{Hb}$ is correct and the average $\mathrm{MCHC}$ and MCV fall out of the action limits, the determination of the hematocrit may be incorrect. It should be taken into account that if only one of the cell constants deviates, this can also be caused by a slight deviation of the parameters from which the cell constants are calculated. A somewhat too small hematocrit and a somewhat too high number of red blood cells may induce the MCV average to fall out of the inferior action limit.

\section{Platelets and white blood cells}

In case of platelets and white blood cells we have nothing to do with cell constants. In the case of cell constants it was a matter of selecting the very normal persons with whom a magnitude originates with a very small physiological deviation so that the truncation limits had to be made very narrow. Here the series average is concerned, and the truncation limits must be set rather wide. Otherwise with a deviation in the average, a number of normal values are classified wrongly as pathological, through which the sensitivity of the series average as a quality control is affected. For platelets and white blood cells the truncation limits are set on the average of \pm 3 S.D., which is $150 \cdot 10^{9} / 1$ for platelets as lower limit and $400 \cdot 10^{9} / 1$ as upper limit; for white blood cells the lower limit is $4.0 \cdot 10^{9} / 1$ and the upper limit is $12.0 \cdot 10^{9} / 1$.

\section{Calculation of the series mean}

Our laboratory has been computerized for the past 2 years $(13,14,15,16)$ and all results are processed and stored with the aid of a Philips ${ }^{2}$ ) computer P9202.

The central processor of the computer has a memory of $32 \cdot 10^{3}$ words $(16$ bits). Connected with this central processor are three disc units with a total capacity of $10.8 \cdot 10^{6}$ words, a line printer (450 lines per minute), a high speed paper tape reader, a high speed paper tape punch, two optical mark readers and 11 teletypes.

The results of the Hemalog are given into paper tape, and this paper tape is fed into the computer. The computer calculates the average for each determination between the truncation limits as indicated above. The results of these calculations are printed with the line printer. An example of this quality control list is given in figure 2.

\section{Results}

\section{Action limits}

Of 30 series which, after full check, were classified as correct, the average and standard deviation of the avarage were calculated.

The action limits were set on two times standard deviations. For convenience they have been rounded off a little (tab. 1).

\footnotetext{
$\left.{ }^{2}\right)$ Philips Medical Systems, Best, Netherlands
} 
Fig. 2. Quality control list of the Hemalog as routinely made by the computer after the results were fed in. On the line "gemeten gemiddelde" the series mean is found for the determination concerned. On the line "attentie" $x x$ indicated that the mean falls outside the action limits.

"totaal aantal" means the number of determinations out of which the mean is determined.

SIICHIIJU MLIISCHL LALSTRATORIA, BREDA

KWA-ITLIISKJVIRJLE-OVERLICHT VAIN: HEMALJG BAICHES: AOG,AOT,AOB,

PERIJOE: $02-10-74 \mathrm{I} / \mathrm{M}$ 02-10-74

TROMBO LEJKO ERY HE HEKRILT CCV CCV/HK
PAGINA:

DATUM : $03-10-74$

IIJO : 11.19 .29

MCV MCH YCHC

PAIIENT-HJNSTLZS:

UMUE $=$ G. VEN WAARDEV

\begin{tabular}{|c|c|c|c|c|c|c|c|c|c|c|c|}
\hline 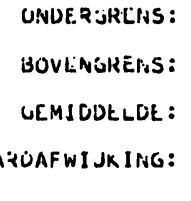 & $\begin{array}{l}\text { aguı } \\
\text { adun } \\
\text { agurı } \\
\text { qaa!। }\end{array}$ & $\begin{array}{r}400 \\
245 \\
85\end{array}$ & $\begin{array}{r}4.00 \\
12.00 \\
7.10 \\
2.50\end{array}$ & $\begin{array}{l}M: \\
V: \\
M: \\
V: \\
M: \\
V: \\
M: \\
V:\end{array}$ & $\begin{array}{l}4,22 \\
3,77 \\
5,34 \\
3,03 \\
4,75 \\
4,34 \\
0,25 \\
0,35\end{array}$ & $\begin{array}{l}M: \\
V: \\
M: 1 \\
V: \\
M: \\
V: \\
M: \\
V:\end{array}$ & $\begin{array}{l}8.70 \\
7.50 \\
10.90 \\
9.70 \\
9.80 \\
8.60 \\
1.10 \\
1.10\end{array}$ & $\begin{array}{l}M: 0.430 \\
v: 0.360 \\
M: 0.490 \\
v: 0.450 \\
M: 0.460 \\
v: 0.406 \\
M: 0.025 \\
v: 0.030\end{array}$ & $\begin{array}{l}M: 0.430 \\
v: 0.360 \\
y: 0.490 \\
v: 0.450 \\
M: 0.460 \\
v: 0.406 \\
M: 0.025 \\
v: 0.030\end{array}$ & $\begin{array}{l}M: \\
V: \\
M: \\
V: \\
M: \\
V: \\
M: \\
V:\end{array}$ & $\begin{array}{l}0.30 \\
0,30 \\
2,00 \\
2.00 \\
1.00 \\
1.00 \\
0.20 \\
0.20\end{array}$ \\
\hline
\end{tabular}

$\begin{array}{rrr}0.0 & 0.00 & 0.0 \\ 999.9 & 9.99 & 99.9 \\ 95.0 & 2.00 & 21.0 \\ 10.0 & 0.20 & 2.0\end{array}$

2 X STAVUAARUAFWIJKING:

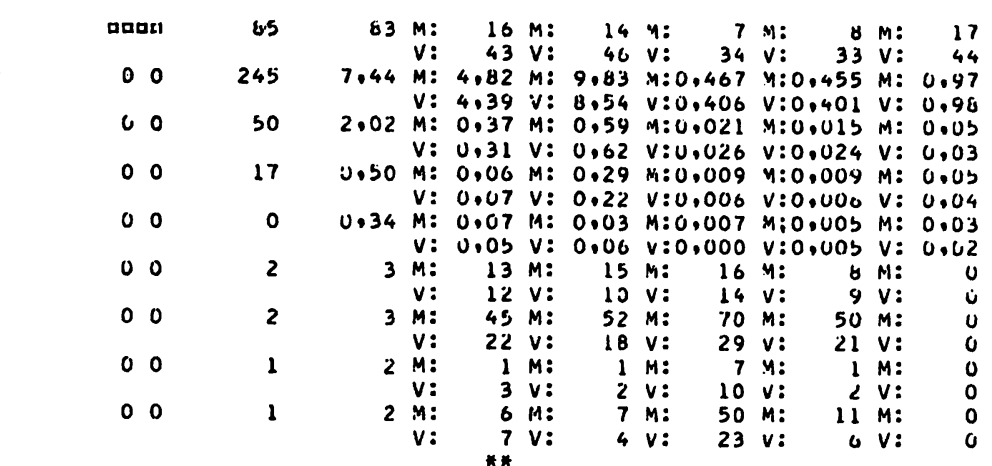

$\begin{array}{rrr}00 & 00 & 60 \\ 91.2 & 1.94 & 20.8 \\ 3.5 & 0.13 & 0.9 \\ 2.0 & 0.04 & 0.4 \\ 0.2 & 0.06 & 0.2 \\ 0 & 0 & 0 \\ 0 & 0 & 0 \\ 0 & 0 & 0 \\ 0 & 0 & 0\end{array}$

ATTEIVTIE:

TJTAAL AANTAL:

JE VLILV ULMIDDELDE:

SIA VUAAZLIAT WI JK IIVG:

MAX. IJELAGIBARL VERSCHIL:

SEMETEN VERSCHIL:

AAVTAL \& ONOLRÚKENNS:

D C UNDLRGRENS:

AANIAL > BUVENSREIHS:

i > LOVLNGKENS:

**

$4 \mathrm{~V}$

**

Tab. 1. Truncation limits and action limits, confidence limits, of white blood cells, red blood cells, hemoglobin of men, hemoglobin of women, and platelets.

\begin{tabular}{lllclcl}
\hline & Unit & $\begin{array}{l}\text { Truncation } \\
\text { Limits }\end{array}$ & Mean Value & S.D. & Action Limits & $\begin{array}{l}\text { Confidence } \\
\text { Limits }\end{array}$ \\
\hline Platelets & $10^{9} / 1$ & $150-400$ & 45 & 9 & $225-265$ & $97 \%$ \\
White cells pat. & $10^{9} / 1$ & $4.0-12.0$ & 7.1 & 0.19 & $6.7-7.5$ & $96 \%$ \\
Hemoglobin (men) & mmol/1 Fe & $8.7-10.9$ & 9.8 & 0.09 & $9.6-10.0$ & $96 \%$ \\
Hemoglobin (women) & mmol/1 Fe & $7.5-9.7$ & 8.6 & 0.13 & $8.4-8.8$ & $88 \%$ \\
MCV & fl & - & 95.0 & 1.56 & $92.0-98.0$ & $94 \%$ \\
MCH & fmol Fe & - & 2.0 & 0.028 & $1.94-2.06$ & $97 \%$ \\
MCHC & mmol/1 Fe & - & 21.0 & 0.24 & $20.5-21.5$ & $96 \%$ \\
\hline
\end{tabular}

Mean value is the mean value of the average; S.D. is the standard deviation belonging to this mean value.

Because the means are distributed normally we can also calculate the confidence limits.

\section{Hemoglobin}

The hemoglobin was checked by means of the hemoglobin of men and women. At the same time a deviation in the mean of the $\mathrm{MCH}$ and $\mathrm{MCHC}$ may indicate that the determination of hemoglobin was not correct. If the $\mathrm{MCH}$ or MCH fall outside the action limits and the hemoglobin mean has moved parallell but not so much that it falls outside the action limits, the hemoglobin was still checked.

The results of 170 batches controlled between 1-10-73 and 1-4-74 are shown in table 2.
If a mean falls outside the action limit this is indicated with an $x$. All combinations of the four possible are taken up under the column "Signal". Under the column "Number of series" the number of series with the same combination of signals is given. Of the 23 series of which one of the means or a combination of means fall outside the action limits, it appears after control that for 10 series the hemoglobin was still right (These series are given in table 2 under the column "correct"). This means that the given signal was false. It is notable that if only one average deviated, this appeared always to be a false alarm.

Of 13 series of which the hemoglobin determination was wrong (given under the column "incorrect" in 
Tab. 2. Hemoglobin. Survey of 23 series (of a total of 170) of which $\mathrm{Hb}$, $\mathrm{Hb}$, $\mathrm{MCH}, \widehat{\mathrm{MCHC}}$ or a combination of these values fall outside the action limits (indicated with $\mathrm{x}$ ).

"Correct" means that after control the determination of the hemoglobin of the corresponding batch appears to be right.

$\overline{\mathrm{Hbo}}=$ average of the scries of the hemoglobin determination for men.

$\overline{\mathrm{Hb}}=$ average of the series fo the hemoglobin determination for women.

$\overline{\mathrm{MCH}}=$ average of a series for the $\mathrm{MCH}$

$\overline{\mathrm{MCHC}}=$ average of a series for the MCHC

\begin{tabular}{|c|c|c|c|c|c|}
\hline \multicolumn{2}{|c|}{ Number of series } & \multicolumn{2}{|c|}{ Signal } & \multirow[b]{2}{*}{$\overline{\mathrm{MCH}}$} & \multirow[b]{2}{*}{$\overline{\mathrm{MCHC}}$} \\
\hline correct & incorrect & $\overline{\mathrm{Hbo}}$ & $\overline{\mathrm{Hb} ?}$ & & \\
\hline & 3 & $\mathrm{x}$ & $x$ & $\mathrm{x}$ & $\mathbf{x}$ \\
\hline \multirow[t]{2}{*}{1} & 1 & $\mathrm{x}$ & & $\mathrm{x}$ & \\
\hline & 1 & & $\mathbf{x}$ & $\mathbf{x}$ & \\
\hline \multirow[t]{2}{*}{1} & 2 & & $\mathbf{x}$ & & $\mathbf{x}$ \\
\hline & 6 & & & $\mathbf{x}$ & $\mathbf{x}$ \\
\hline $\begin{array}{l}1 \\
3\end{array}$ & & $\mathbf{x}$ & $\mathbf{x}$ & - & \\
\hline 1 & & & & $\mathbf{x}$ & \\
\hline 3 & & & & & $\mathbf{x}$ \\
\hline
\end{tabular}
series the calibration has been effected on a sample which did not contain the given value. In 2 series too low an average was due to an incorrect function of a flow regulator. In 4 series a mistake in the average was caused by a leaking valve. In 5 series we were not able to find exactly what was wrong with the hemoglobin determination. From table 2 it appears that if all means fall outside the action limits the hemoglobin determination was always wrong.

\section{Red blood cells}

When the average of the MCV and/or the average of the MCV falls outside the action limits, a deviation could be caused by wrong determination of the number of red blood cells.

When only the average of the MCV fell outside the action limits and the $\mathrm{MCH}$ average had moved in parallell, but not so much that it fell outside the action limit, the measured red blood cells were reviewed. The same procedure was followed when the average of the $\mathrm{MCH}$ gave a signal and the average of the MCV had moved in parallell.

In table 3 the results are given of the 170 controlled series. In 7 series both the MCV and the MCH fall outside the action limits. In all these seven series the measurement of red blood cells was not correct, this is $4.1 \%$ of the total. The cause of this mistake could be found in 5 series. For two series a false calibration was the reason that the action limits fell outside the action limits. Fot two series the lamp of the optical
Tab. 3. Red blood cells. Survey of 12 series (of a total of 170) of which the $\overline{\mathrm{MCV}}$ or the $\overline{\mathrm{MCH}}$ fell outside the action limits. (indicated with $x$ ) "Correct" means that after control the determination of the red blood cells of the corresponding series appears to be right.

$\overline{\mathrm{MCV}}=$ the average of the series of the MCV determination $\overline{\mathrm{MCH}}=$ the average of the series of the $\mathrm{MCH}$ determination

\begin{tabular}{llll}
\hline $\begin{array}{l}\text { Number of series } \\
\text { Correct }\end{array}$ & Incorrect & & \multicolumn{2}{l}{ Signal } & \\
\hline & $\overline{\mathrm{MCV}}, 1$ & $\overline{\mathrm{MCH}}$ \\
\hline 3 & 7 & $\mathrm{x}$ & $\mathrm{x}$ \\
\hline 5 & & $\mathrm{x}$ & $\mathrm{x}$ \\
\hline
\end{tabular}

Tab. 4. Hematocrit. Survey of 8 series of which the $\overline{\mathrm{MCV}}$ and or the $\overline{\mathrm{MCHC}}$ fell outside the action limits (indicated with $\mathrm{x}$ ). Correct means that after control the determination of the hematocrit of the corresponding series appears to be right.

$\overline{\mathrm{MCV}}=$ the average of the series of the MCV determination

$\overline{\mathrm{MCHC}}=$ the average of the series of the MCHC determination

\begin{tabular}{llll}
\hline Correct & Incorrect & $\overline{\mathrm{MCV}}$ & $\overline{\mathrm{MCHC}}$ \\
\hline 3 & 3 & $\mathrm{x}$ & $\mathbf{x}$ \\
\hline 3 & 2 & & $\mathbf{x}$ \\
\hline
\end{tabular}

system was worn out and at one series a pump tube was too old. In two series we could not detect exactly what was wrong with the determination of the red blood cells. In 5 series the average of either the MCV or $\mathrm{MCH}$ gives a signal. In all these cases this appears to be a false signal.

\section{Hematocrit}

If the $\mathrm{MCV}$ and the $\mathrm{MCHC}$ lie outside of the $2 \mathrm{~S}$ reliabjlity limits, the measurement of the hematocrit may be incorrect. In case of a deviation of one of these averages it has to be verified whether the other average moves in parallel. The results of 170 controlled series are given in table 5. At three series the given signal appears not to be right. The hematocrit determination appears to be wrong in 5 series. In one of these series we could detect what was wrong.

The detected fault in all these five series was not greater than 1.2 hematocrit $\%$.

Of the 170 series the hematocrit determination was wrong in $2.9 \%$ of the series.

\section{White blood cells}

The distribution of the average of the white blood cells falling outside the action limits is as indicated in table 5 . 
Tab. 5. White blood cells. Survey of the 27 series of which the series average of the white blood cells fell outside the action limits. The observed series averages are divided in 6 groups.

\begin{tabular}{lll}
\hline \multicolumn{2}{l}{ Series average between } & Number \\
\hline$<6.4$ & $10^{9} / 1$ & 5 \\
$6.4-6.6$ & $109 / 1$ & 3 \\
$6.6-6.7$ & $109 / 1$ & 7 \\
$7.5-7.6$ & $109 / 1$ & 1 \\
$7.6-7.8$ & $10^{9} / 1$ & 3 \\
$>7.8$ & $10^{9} / 1$ & 8 \\
\hline
\end{tabular}

In 7 of these 27 series an error was established. This is $4.1 \%$ of the total number of series. In 3 of the 7 wrong series we could detect the fault. In 2 series too low a value of the average was caused by a lamp which had to be replaced and in 1 series too low a value was caused by a plugged filter.

In 4 series it was not possible to determine precisely what was wrong.

In 20 series the mean of the white blood cells gave a false alarm.

\section{Platelets}

The series averages of 170 checked series lie 18 times outside the action limits distributed as indicated in table 6.

Only once could it be established that too low an average was caused by a wrong calibration. When checking no mistake could be established for the other 17 series. The frequent occurrence of averages that were somewhat too low is probably due to keeping the samples too long, whereby the number of platelets is somewhat decreased.

Tab. 6. Pletelets. Survey of 18 series of which the series average of platelets fell outside the action limits. The observed series averages are divided in four groups.

\begin{tabular}{llc}
\hline Series average between & Number \\
\hline $210-220$ & $10^{9} / 1$ & 4 \\
$220-225$ & $10^{9} / 1$ & 10 \\
$265-270$ & $10^{9} / 1$ & 2 \\
$270-280$ & $10^{9} / 1$ & 2 \\
\hline
\end{tabular}

\section{Discussion}

Any determination is affected by a certain error. We can differentiate errors into random and systematical errors. In hematology we can find random faults by a discrepancy between the values of the Hemalog and the differential count of white blood cells. At a low MCHC there has to be hypochromasy under the micros- cope. At a low MCV there will be microcytes. The number of white blood cells and platelets we can check roughly with the values which we find by the differential count.

This method does not detect small systematic errors. If, however, there are enough patient values available which do not deviate much from the normal area, it is possible to use them to detect systematic errors. The detection of errors is based on the fact that a value can be compared with another, of which the result is known. In the case of patient values the average of all values which lie within the truncation limits is used for this. This mean value must have been established during a sufficiently long period. We have used the average of patient values of a series. The only condition is that the number of patient values is large enough. The advantage of calculating the series average to the day average is that there is no need to delay the calculation of the average till the end of the day. This implies that any established error can immediately be corrected before a new series is determined and in the second place that the error is detected before any results have been reported, which is mostly not the case when calculating the day average.

Comparing the coefficients of variation of the averages with the coefficient of variation of control samples (7) it is notable that the coefficients of variation for hemoglobin, $\mathrm{MCV}, \mathrm{MCH}$ and $\mathrm{MCHC}$ are smaller than those for control samples. This means that this method indicates any deviation earlier than control samples.

For white blood cells the coefficients of variation of both are about the same and for platelets the coefficient of variation of the control sample is obviously smaller. Another advantage of calculating averages to testing samples is that the analyst does not know the values, so that the results are "unbiassed".

The sensitivity of this method depends on the deviation which can occur in the average. By establishing truncation limits this deviation is limited considerably. The sensitivity is defined as the quotient $(R)$ of the deviation of the average (dQ) and the deviation in the accuracy (dA) (11). By establishing truncation limits $R$ is always smaller than $1(11,17)$. This means that if a deviation has been determined in the average, the correct value has to be established experimentally. If the error is of such a nature that values are concerned which continously are too low (errors in calibration, dilution), then all values can be corrected by a value determined experimentally. Although Owen \& Cambell (17) say that calculating the average of the series is not suitable, it appears to be quite satisfactory for checking the $\mathrm{Hb}$, red blood cells and hematocrit. This is because the deviation in the cell constants MCH, MCHC, MCV and hemoglobin is small. For none of the 5 values which Owen \& Cambell examined (chloride, $\mathrm{CO}_{2}$, potassium, sodium, urea) is the quotient of standard deviation and 
average less than 0.02 . For $\mathrm{Hbo}, \mathrm{Hb}$ \%, $\mathrm{MCV}, \mathrm{MCH}$, MCHC this is indeed the case (tab. 1).

The calculation of the average for platelets and white blood cells appears to be useful, though this method is less sensitive. The cause of this lies in the fact that the deviation in the average is very great. We have the impression that this great deviation is caused because no homogeneous population has been found yet. If a homogeneous population with a sufficiently great number of values is found, it seems possible in every way to make the method more sensitive. This will be looked into further.

\section{Acknowledgements}

We gratefully acknowledge the assistance of Miss $A . W . M$. Hermus with the experiments and Mr. A. Ms H. van Rooij for making the quality control program.

\section{Literature}

1. Hoffmann, R. G. \& Waid, M. E. (1963), Amer. J. Clin. Pathol. 40, 263-269.

2. Frankel, S. \& Ahrin, R. C. (1967), Amer. J. Clin. Pathol. $48,248-250$.

3. Hoffmann, R. G. \& Waid, M. E. (1965), Amer. J. Clin. Pathol. 43, 134-141.

4. Dorsey, D. B. (1963), Amer. J. Clin. Pathol. 40, 457-464.

5. Ball, B. S., Elashoff, R. M., Heilbron, D. C. \& Couperus, J. (1974), Amer. J. Clin. Pathol. 61, 473-481.

6. Van Kampen, E. J. \& Zijlstra, W. G. (1968), Clin. Chim. Acta 6, 538-544.

7. Rutten, W. P. F., Scholtis, R. J. H., Schmidt, N. A. \& van Oers, R. J. M. (1975), this j 13, 387-393.

8. Becker, S. M., Pribor, H. C. \& Dickson, W. (1970), Technicon International Congres, New York, 397-401.

9. Frederik, W. S. (1974), J. Occ. Med. 16, 313-321.

10. De Jonge, H. J. (1963), Inleiding tot Medische Statistiek, Wolters Noordhof, Groningen.
11. Lewis, P. W. \& Dixon, K. (1971), Clin. Chim. Acta 35, 2132.

12. Withby, L. G. \& Mitchell, F. L. (1967), Adv. Clin. Chem. 10,65 .

13. Scholtis, R. J. H. \& Hempenius, K. (1972), Organisation des laboratoires, Biologie Prospective Pont á Mousson, 301-304, Schweizer, Paris.

14. Scholtis, R. J. H. \& Hempenius, K. (1972), Computer en medische zorg, 42-51. Stafleu B.V., Leiden.

- 15. Hempenius, K. \& Scholtis, R. J. H. (1974), Medinfo 74, Stockholm.

16. Scholtis, R. J. H. (1974), Een computer systeem voor geautomatiseerde informatieverwerking in een medisch laboratorium. Philips Nederland B.V., Eindhoven

17. Owen, J. A. \& Cambell, D. G. (1968), Clin. Chim. Acta 20, 327-334.

Drs. W. P. F. Rutten Stichting Medische Laboratoria Ignatiusstraat 11

Breda 